\section{Enhanced weathering of wollastonite in agricultural soils and mineral-soil- plant interactions}

MR. REZA KHALIDY, MSC, FATIMA HAQUE, RAFAEL M SANTOS AND YI WAI CHIANG

University of Guelph

Presenting Author: rkhalidy@uoguelph.ca

To lock atmospheric $\mathrm{CO}_{2}$ at adequate timescale, fast weathering silicates, including wollastonite, can be applied to soils to accelerate $\mathrm{CO}_{2}$ sequestration via enhanced weathering. When finely crushed wollastonite interacts with soil pore water, alkaline earth metal cations released during mineral weathering gradually react with carbonate anions. Under favorable conditions, the formation and accumulation of pedogenic carbonates in the soil has been observed. Our studies to date have assessed the application of wollastonite (mined from the Saint Lawrence Wollastonite Deposit) in agricultural soils of Southern Ontario (Canada), and its compatibility with several agricultural crops.

To investigate the role of plants, pot experiments were conducted by growing leguminous beans and non-leguminous corn in wollastonite-amended soil [1]. Subsequently, a microplot study was conducted to determine the effect of different dosages of wollastonite on three types of legumes [2]. In parallel, field trials have been carried out to study the changes incurred to potato farming and horticultural soils as a result of the application of wollastonite, and to study the effects of wollastonite application on a soybean crop within a growing season [3]. In our latest field experiment, we investigated soil inorganic carbon (SIC) content over the soil's vertical profile (0$30,30-60$, and $60-100 \mathrm{~cm}$ depths) in a field microplot of winter rye [4]. SIC has been analyzed using calcimetry, CHNS, and thermogravimetric analyses, and soil mineralogical assessment has been performed using X-ray diffraction and scanning electron microscopy.

Results obtained from our studies are of significance for climate change mitigation via enhanced weathering in soils, and to demonstrate the synergistic plant growth benefits of wollastonite amendment. The co-benefits of wollastonite soil amendment $\left(\mathrm{CO}_{2}\right.$ sequestration and crop health) can thus encourage producers to effectively use this mineral to contribute towards global climate change mitigation without compromising their produce.

[1] Haque, Santos, Dutta, Thimmanagari \& Chiang (2019), ACS Omega 4(1), 1425-1433. [2] Haque, Santos \& Chiang (2020), Frontiers in Plant Science 11, 1012. [3] Haque, Santos \& Chiang (2020), International Journal of Greenhouse Gas Control 97, 103017. [4] Khalidy, Haque, Chiang \& Santos (2021), Journal of Visualized Experiments, e61996.
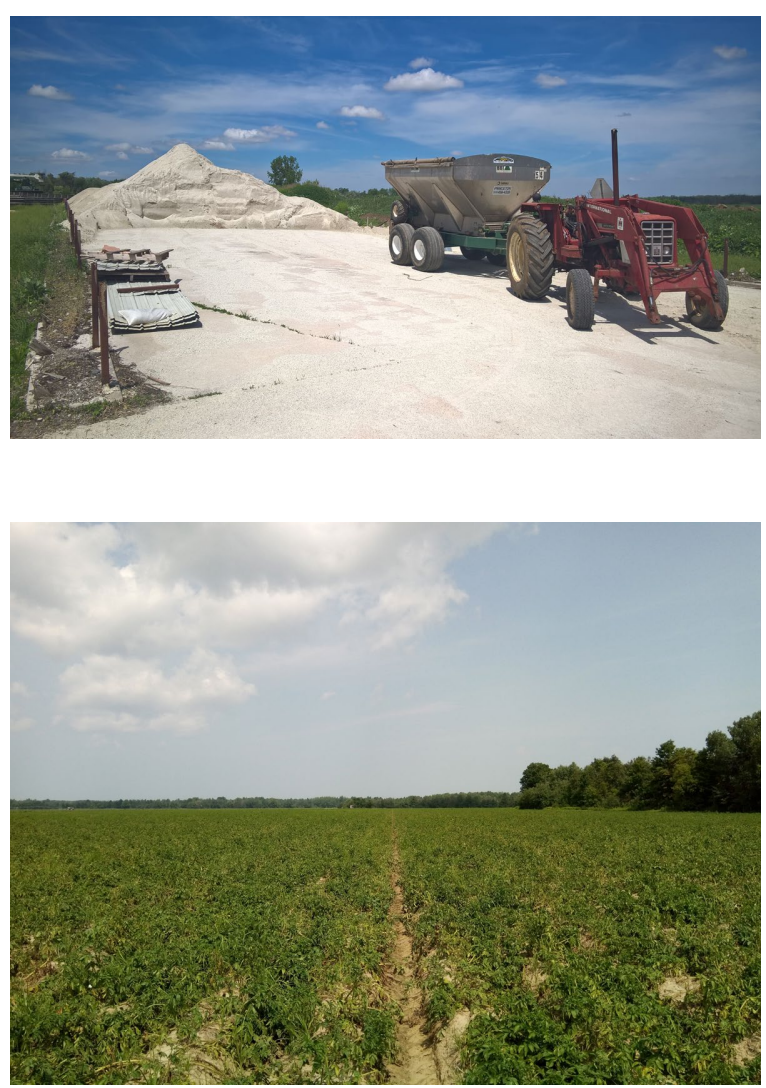